\title{
Interactive Visualization Tool as an Element for Planning Educational Solutions on the Digital Footprint of Companies
}

\author{
Milekhina O.V.* Adova I.B. Fomin V.A. \\ Faculty of Business, Novosibirsk State Technical University, Novosibirsk, 630087, Russia \\ *Corresponding author. Email: olga.milekhina@gmail.com
}

\begin{abstract}
The results of designing a tool for supporting interactive planning of the formation of hard, soft, and digital competencies (HSDS) in the educational community have been provided. The main characteristics of the position (HSDS, length of service, salary, etc.) that the graduate will apply for have been identified on the basis of the formation of a digital footprint of companies. The paper provides an overview of domestic and foreign software apps to support educational solutions in a pair of "Student-Lecturer" stakeholders. The paper presents a schematic diagram of an interactive tool for planning the educational process based on the formation of a digital footprint of companies as part of the placement of information about employers' vacancies on aggregator websites. The result of displaying an interactive map on a specific example has been justified and provided.
\end{abstract}

Keywords: digital footprint, educational decision-making, interactive map, stakeholder

\section{INTRODUCTION}

The specialized employment of graduates of higher educational institutions is one of the acute problems of the youth labor market. Upon completion of education, many graduates realize the lack of demand for the competencies they have formed in the business environment [1]. Researchers have recorded that the level of qualification has a positive effect on the level of field-oriented employment $[2,3,4]$. Moreover, only every third graduate is employed in specialized jobs, regardless of the economic parameters of the region [5]. Leaving aside the issues of the opportunistic behavior of individual students during their studies and their low level of digital literacy, we can assume the lack of instrumental support in the process of forming the sum of professional competencies. This study is aimed at designing a tool for supporting interactive planning of the formation of hard, soft, and digital competencies (HSDS) of the subjects of the educational process - students and lecturers. The design thinking methodology is used. With its help, we have found that for two different classes of users (in terms of the entry-level professional competencies), it is necessary to develop a specialized and, at the same time, simple tool. To do this, we have reviewed the literature on existing software apps, their purpose and scope. Based on the results obtained, a tool has been designed and software implemented to display the results of requests from students and faculty about individual characteristics of a particular segment of the labor market.
Publication structure: Section 2 provides a brief overview of domestic and foreign software apps that support the educational process in a pair of "Student-Lecturer" stakeholders, important elements of the tool design. Section 3 discloses the design process and software implementation of the tool. Section 4 presents the results, including a demonstration of the result of the software, while Section 5 discusses them, presents conclusions, and outlines future research.

\section{BACKGROUND}

The analysis of literary sources and research results has shown that the issues of instrumental support for the formation of hard, soft, and digital competencies have not been adequately studied in terms of the effectiveness of the educational process and the generated value for the business. The demand for a graduate is determined by the embedded system of values and the sum of competencies, the request for which the business community generates at any given time. At the same time, the satisfaction of the needs of employers should be ensured by the sum of competencies to ensure routinized (current) and intellectual (strategic) processes of the organization. At the start of a career, hard, soft, and digital competencies should ensure minimal time spent on including a young specialist in the organization's business processes and solving assigned tasks. In terms of prospects, the graduate should have strategic thinking, be able to produce innovative ideas, work with a wide range of stakeholders 
(Multiplicity of Stakeholders), and be able to find compromise solutions, "...to understand the nature and implications of stakeholder capitalism" [6]. Accordingly, the subjects of the educational process should have instrumental support in planning the process of forming the required competencies at a particular workplace.

Theoretically, this process is supported by existing tools (software). In particular, A. Karpov offered support for interaction of knowledge generation environment (universities, research institutions) and the environment for their technological development (business community) based on an engineering educational platform. Thus, the formation of relevant HSDS subjects of the educational process is built on the basis of the implementation of production transactions between agents of a network engineering technological platform [7]. N. Bazhenova. $\mathrm{S}$. Ivanova, and $\mathrm{S}$. Razin suggested publishing a resume and a portfolio of students and employers' vacancies on a specialized university website [8]. A. Alexandrov proposed a prototype of an automated information system for the interaction of students and employers. The system provides accounting and monitoring of students' practices and employment [9]. M. Elmutarov pointed out the shortcomings of the instrumental support of the monitoring process of university graduates in Uzbekistan and proposed a prototype of a graduate monitoring system with a core in the form of a database (DB) [10]. L. Vadova analyzed the problems of employment of graduates, formulated the thesis that the bachelor is perceived by employers as "the source material for training a specialist". She proposed the creation of a database of students, which ensures the satisfaction of employers' requests for knowledge acquired at the university (portfolio) and other achievements. It is assumed that this knowledge will help minimize the cost of inclusion in work processes [11]. D. Boikov presented the experience of using the advisory service to find work and personnel on the 1C-Bitrix platform [12]. Summarizing the areas of domestic software application, a significant stratification of tools should be noted. Basically, they provide the implementation of certain functions of the interaction process between applicants (university students) and employers. The ideology of an engineering educational platform allows the formation of HSDS competencies of the educational process subjects, but the concept is provided at a macro level. O. Maksimenkova and A. Neznanov systematized the most modern tools for creating "collaborative spaces" $[13,14]$. In our context, collaboration means the interaction of two or more subjects of the educational process, united by a common goal (the sum of HSDSs), which each subject individually cannot achieve. In the framework of traditional education, this is the "StudentLecturer" collaboration. "Hybrid learning" (a combination of traditional and distance learning) simplifies the feedback between the subjects of the educational process and it can expand this established network of collaborators by representatives of the business community, for example, during the implementation of joint projects [15]. The application of the methodology of spaces supports the educational process in terms of the implementation of certain functions: support for novice programmers (http://repl.it), creating smart maps (http://coggle.it), working with bibliography (http://mendeley.com) and citation (http://citavi.com), designing ontologies (http://protege.stanford.edu), etc.

The implementation of hybrid learning involves expanding the roles of subjects of the educational process. The study of E. Borisova recorded three options for communication between lecturers and students in the process of classroom (face-to-face learning), independent (self-study learning), and distance work (distance learning) [15]. Each interaction option assumes its own lecturer role: as a generator of information content, a message generator, and a verifier of students' educational trajectories. Student roles characterize their position in the educational process in terms of activity, including in terms of HSDS planning: silent student (Student's role Quiet), student missing classes (Student's role Missing), active student (Student's role Active), less active student (Student's role Less active member), as well as roles in solving assigned tasks: leader (Student's role Leader/Guide), coordinator (Student's role Facilitator), expert (Student's role Observer) [16]. Role differentiation allows us to conclude a different value interpretation of the benefits of exploiting collaborative spaces. Improving the effectiveness of the communication process and, accordingly, the effectiveness of the formation of competencies provides the needs of the active part of students and lecturers (i.e. those subjects who are already involved in innovative processes). In contrast, the silent students (Quiet Student) will continue to passively monitor the introduction of innovations in the educational process, and students who miss classes will exhibit opportunistic behavior.

The inclusion of the inactive part of students and lecturers is possible through their informing about demanded competencies based on data from objective sources. We have developed an interactive tool for planning the method of forming HSDS based on a digital footprint that provides such an opportunity.

By digital footprint we mean information deliberately or unintentionally left during a stay in the digital space with the further possibility of identifying its source [17]. During the design of the interactive tool, one of the properties of the digital footprint has been used: the entered information is almost impossible to delete, and it becomes publicly available. Thus, the tool for creating a digital footprint of a company in the labor market seems relevant.

The search for works in English has been carried out on the Web of Science platform. The paper uses the approach of selecting publications for a systematic review, as well as for determining the type of information visualization, the results of conceptual and logical design of interactive tools for stakeholder interaction. At the first stage, the number of publications has been estimated separately for the descriptors: "stakeholder" (116,500 publications), "stakeholder" \& "digital footprint" $(1,799)$, and "stakeholder" \& "mapping digital footprint" (239). At the second stage, a request is formulated regarding approaches 


\section{METHOD}

to information visualization in the educational process - "mapping digital footprint" \& "student". Only one publication from the two lists received is devoted to the results of research by the R. Martinez research team on the mapping of modeling processes of group collaboration based on digital and sound footprints. The theoretical model of joint learning, built by researchers, was confirmed by testing on the data of multi-display software [18]. The combined use of «stakeholder» \& «digital footprint» descriptors made it possible to localize 27 publications over the years, which are distributed across 15 subject areas, which testifies to the universality of the tool. At the same time, only two works were performed in the field of education. A paper by K. Rosenbusch is dedicated to rethinking the role of education and faculty in a transforming digital environment. The problems and possibilities of using technologies of online, mobile, and blended learning to increase online and geographical reach of the audience have been highlighted [19]. The second publication by N. Nouman and A. Umer is dedicated to web navigation and usability analysis of educational websites of more than a hundred educational institutions in Pakistan. It is concluded that there is a need for purposeful formation of the university's digital footprint and parameters are proposed for checking the website navigation [20].
The designed tool provides the ability to collect relevant information on the basis of monitoring the digital footprint (company vacancies), its accumulation and storage. In the study, the task of modeling the structure of functional subsystems taking into account the visualization of the digital footprint has been solved, and the technology has been developed and implemented in the form of several interrelated programs.

The structure of the functional subsystems of the tool has been defined at the level of two interconnected sets of tasks: creating a platform for placing a digital footprint (creating a website, hosting a website, creating a domain), as well as a platform for the subsystem of data collection, storage, and visualization.

The structure of the tool includes six base blocks (Figure 1):

1) Site block - determining the style of the website, choosing the color scheme, determining the layout of pages, describing the format of blocks with content, compatibility with various browsers and devices;

2) Hosting block - storing the website on the server, delimiting the rights to administer the website, operating the backup system, providing reports with errors in the case of the website malfunction, registering a domain name, gaining access to the website by domain name; 


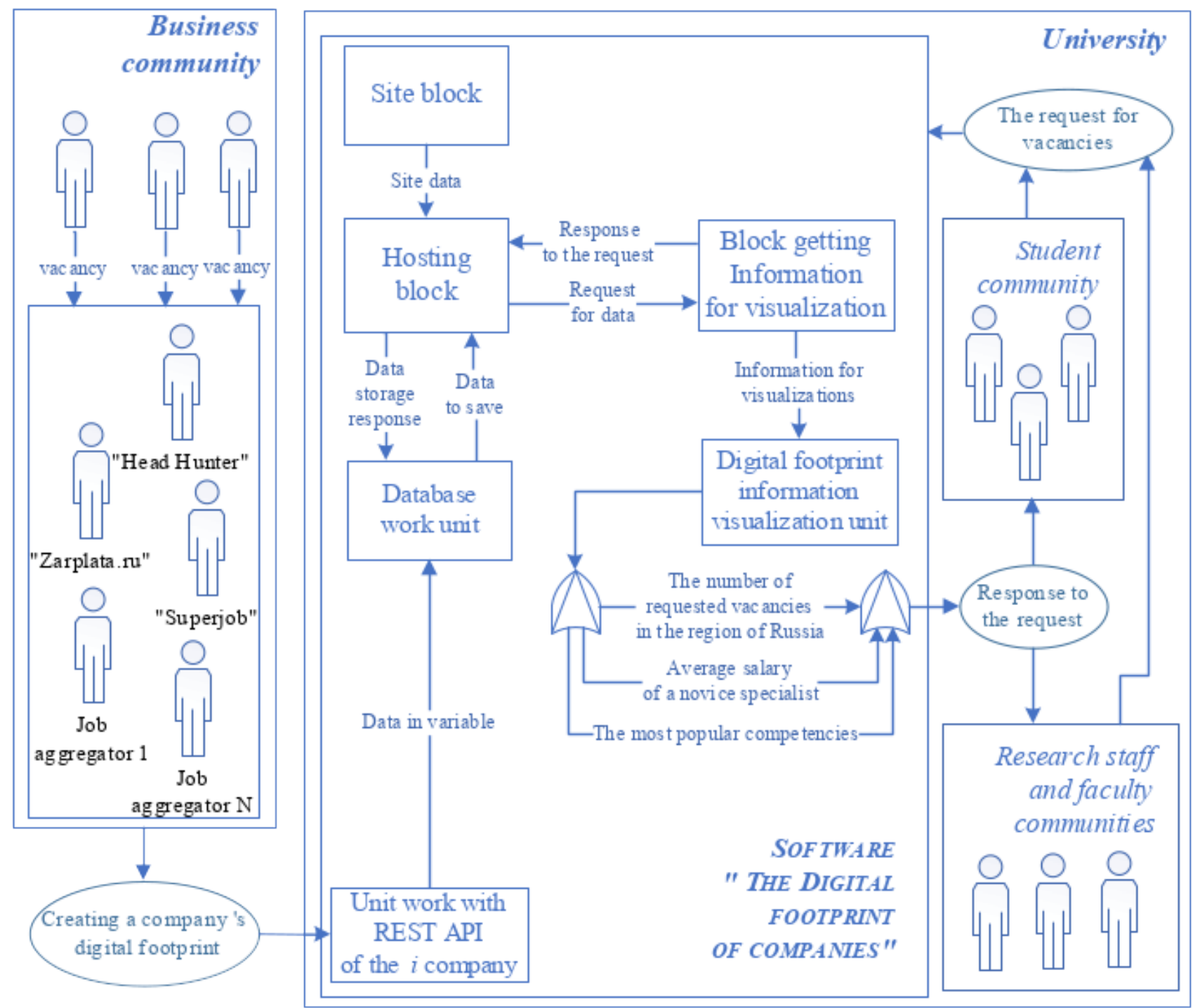

Figure 1 - Schematic diagram of an interactive educational process planning tool based on the formation of a digital footprint of companies

3) Database block unit - remote connection to the database, creating a database for the website, creating tables in the database, writing job data to tables, deleting obsolete data and writing new ones;

4) Unit work with REST API of the $i$ company generating queries to RESTAPI, receiving query results, storing query results in a variable;

5) Block getting information for visualization on the digital footprint visualizes an interactive map of the regions of the Russian Federation with the display of information on the vacancies of a particular profession, creates diagrams;

6) Digital footprint information for visualization unit generates database queries, gets relevant data from the database.

Moreover, the tool implemented functions for storing data with a mark of the point in time at which they were relevant, as well as changing data structures during the operation of the tool. The information flows of the digital footprint generation tool are classified in relation to the digital footprint generation system (incoming, outgoing, and internal information flows), degree of openness (public and non-public information), and subjectivity.

The software implementation of the technology for creating a digital footprint of companies required the use of two programming languages (JavaScript and Python), a query language (SQL), and page layout languages (HTML and CSS).

Thus, the conceptual scheme of the software implementation of the digital footprint generation has been designed on the basis of the sequential implementation of two stages: creating and configuring the system (deployment, filling data), and designing technology for working with data (updating / updating data / data output). 
The collected, accumulated, and stored data in the system has been placed in the hosting repository (in the embedded file system) or in the database (created by the user on the hosting). The end result of the system has been clustered and stored in the database data on vacancies. Embedded visualization tools allowed displaying data relevant to the request of users (subjects of the educational process).

\section{RESULTS}

Thus, an interactive tool to provide information collection, processing, storage and output has been designed and software implemented. The choice of what information will be worked on depends on the task set for the system. Almost any work with a digital footprint can be reduced to the presented fundamental model (taking into account the introduction of minor changes depending on the chosen subject area).

Website development in HTML, CSS, JS and software implementation of digital footprint visualization in JS, HTML, CSS, and PHP made it possible to get the resultan interactive map of the Russian Federation with the actual data on the number of vacancies for a particular specialty in the regions of the Russian Federation, the level of salaries, and the most sought-after professional competencies of potential candidates (Figure 2).

Thus, the process of working with an interactive map has three main stages: (a) the context of the problem being solved and the purpose of working with the interactive map are determined, (b) the workplace of interest is selected and the request for the interactive map is formulated, and (c) the results of the work are analyzed with an interactive map.

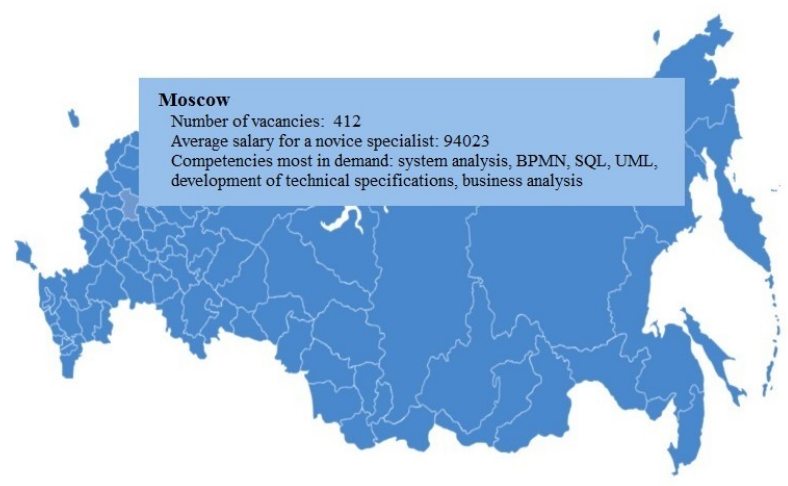

Figure 2 - Result of displaying an interactive map with data on System Analyst vacancies

Here is one of the applications of the presented HSDS interactive planning tool. The student expects to work as a system analyst, he/she is active, ready to develop independently in the professional field, and mobile. The purpose of working with an interactive map is to study the labor market offers for the System Analyst vacancy. On the website, the student enters the appropriate request and receives a response. Moving the mouse on the interactive map shows the offer of jobs in the regions of the Russian Federation. Figure 2 shows the job offer of a systems analyst in Moscow. At the time of the request, this is 412 vacancies, the average declared salary for the chosen specialty in this region is 94,023 rubles per month, the most demanded competencies are SQL, UML, BPMN, development of technical tasks. Let the student understand at the moment that he/she is not familiar with the BPMN (Business Process Management Notation) language. The student resorts to an active experiment and establishes that BPMN is indicated in the requirements for the candidate in many vacancies of a system analyst in the regions of the Russian Federation that interest him/her. Further, he/she can build competence in many ways, including:

1) establish contact with a lecturer who solves practical problems using this tool,

2) to join the project with specialists in this field in the format of project training;

3) to independently find a subject at the university, the content of which provides for the formation and development of this competency, to obtain permission from the faculty leadership, and to attend classes in this academic subject;

4) to establish contact with other students interested in the formation of this competency and to turn to the management with a request to organize the corresponding elective course;

5) to independently learn the BPMN business process modeling language and to shape a competency that is in demand on the labor market.

The presented interactive map has been created for several professions: systems analyst, business analyst, web developer, web designer, 1C programmer, IT project manager, Internet marketer.

\section{CONCLUSION}

The proposed version of the interactive map will benefit all interested parties in the educational process. The State, university entrants, and their parents (acting as investors in the education of children), as well as students, receive the opportunity of professional orientation and selfdetermination. University entrants who have already decided on a future profession, as well as senior students, can form their own professional educational trajectory through the formation of competencies relevant in the region of the proposed location. The quality of the educational process will be improved through an understanding of the requirements for a potential employee, the functionality of his/her future work and context. The accumulation of information in a data warehouse is of interest for a separate empirical study.

Touching upon issues of university activities strategy, search for potential stakeholders, formation of cooperation proposals and subsequent contacts, it is possible that the proposed interactive map will allow choosing the most promising professions. Such a core will make it possible to purposefully formulate professional competencies 
https://kosygin-rgu.ru/filemanag/Uploads/news/31-032016.pdf

[9] Electronic archive of TSU. [Electronic resource] Mode of access: http://earchive.tpu.ru/handle/11683/53091?locale=en

[10] M. K. Elmutarov Designing Information Support for Monitoring University Graduates // Voprocy Nauki, 2017, [Electronic resource] - Mode of access: https://cyberleninka.ru/article/n/proektirovanieinformatsionnogo-obespecheniya-dlya-monitoringavypusknikov-vuzov

[11] L. Yu. Vadova System of Interaction Between Universities and Employers in the Preparation of Future Specialists // International Journal of Applied and Fundamental Research 2016. [Electronic resource] Mode of access: https://applied-research.ru/ru/issue/view? id $=500$

[12] D. I. Boikov Using the Functionality of Products "1C: Library" and Portals "1C: Bitrix" for Employment of Students and Graduates / New Information Technologies in Education, 2019 [Electronic resource] - Mode of access: https://educonf.1c.ru/conf2019/thesis/4154/

[13] O.V. Maksimenkova, A.A. Neznanov Collaborative Technologies in Education: How to Build an Effective System for Blended Learning? // University Management: Practice and Analysis, 2019; 23(1-2), pp. 101-110

[14] J. Salmons, L. Wilson (ed.). Handbook of Research on Electronic Collaboration and Organizational Synergy. IGI Global, 2009, 1026 pp.

[15] Borisova E. V. The Role of the Teacher in the Digital Education System // The Human Capital, 2020, No. 3(135) pp. 104-109 [Electronic resource] - Mode of access: https://humancapital.su/wp-content/uploads/2020/03/20 2003 p104-110.pdf

[16] J.A. Marcos-García, A. Martínez-Mones, Y. Dimitriadis. DESPRO: A Method Based on Roles to Provide Collaboration Analysis Support Adapted to The Participants in CSCL Situations // Computers \& Education 82, 2015 pp.335-353.

[17] Reference and Self-Education Tool about Information Technology. [Electronic resource] - Mode of access: https://whatis.techtarget.com/definition/digital-footprint 
[18] R. Martinez, J. Kay, R. James. Modelling Symmetry of Activity as an Indicator of Collocated Group Collaboration // $19^{\text {th }}$ International Conference on User Modeling, Adaptation and Personalization (UMAP 2011) Girona, SPAIN

[19] K. Rosenbusch Technology Intervention: Rethinking the Role of Education and Faculty in the Transformative Digital Environment Advances in Developing Human Resources, Volume 22, pp 87-101; doi: $10.1177 / 1523422319886297$

[20] N. Nouman, A. Umer Web Navigation and Usability Analysis of Educational Websites in Pakistan // 2019 7th International Conference on Digital Information Processing and Communications (ICDIPC) 